\title{
COBERTURA INFORMATIVA DE LA GUERRA DEL GOLFO EN CASTILLA-LA MANCHA: DISCURSO EN LA PRENSA REGIONAL
}

\author{
NEWS COVERAGE OF THE GULF WAR IN CASTILLA - LA MANCHA: \\ DISCOURSE IN THE REGIONAL MEDIA
}

\author{
Álvaro de la Paz González \\ Universidad Complutense. Madrid/España \\ alvarodelapaz@ucm.es
}

Recibido/Received: 12/06/2018

Modificado/Modified: 22/07/2018

Aceptado/Accepted: 10/09/2018

\section{RESUMEN}

La clase política castellano-manchega y los medios de comunicación regionales no fueron ajenos a la participación española en la Guerra del Golfo de 1991. Prensa y representantes públicos abordaron el conflicto desde la proximidad y centraron su relato en los soldados desplazados, el servicio militar obligatorio, el alza de los precios y las manifestaciones por la paz. El sistema mediático castellanomanchego, poco articulado y dependiente de Madrid, favoreció el empleo de marcos sencillos y generó una cobertura superficial. El mensaje político en la región reiteró un discurso similar al estatal, aunque la visión de la guerra en Castilla-La Mancha incorporó elementos propios como la tensión entre el Gobierno autonómico y el Ministerio de Defensa por el uso de determinados espacios naturales o el caso de los insumisos de Albacete. Se cuantificarán las informaciones generadas en cuatro medios impresos y se analizarán cualitativamente según el contenido y el uso de frames.

\section{PALABRAS CLAVE}

Guerra del Golfo; framing; Castilla-La Mancha; medios de comunicación; manifestaciones.

\section{SUMARIO}

1. Introducción. 2. Metodología. 3. La nueva región como res política. 4. La prensa de Castilla-La Mancha en los noventa. 5. Análisis informativo de Lanza. 6. Análisis informativo de los otros medios. 7. La guerra en la política regional. 8. Conclusiones. Bibliografía.

\footnotetext{
ABSTRACT

The political class and the regional media of Castilla-La Mancha were not oblivious to Spanish participation in the 1991 Gulf War. Press and public representatives approached the conflict from close proximity and focused their narrative on the displaced soldiers, compulsory military service, rising prices and demonstrations for peace. The media system of Castilla-La Mancha, little articulated and dependent on Madrid, favored the use of simple frames and generated superficial coverage. The political message in the region reproduced a similar discourse to that of the State, although the vision of the war in Castilla-La Mancha incorporated its own elements, such as the tens situation between the autonomous government and the Ministry of Defense because of the use of certain green spaces or the case of the conscientious objectors of Albacete. The information of four printed media will be quantified and qualitatively analyzed according to the content and use of frames.
} 


\section{KEYWORDS}

Gulf War; Framing; Castilla-La Mancha; Media; Political Protests.

\section{CONTENTS}

1. Introduction. 2. Methodology. 3. The New Region as Res Politics. 4. The Castilla-La Mancha Press of the 1990s. 5. Informative Analysis of Lanza. 6. Informative Analysis of other Media. 7. The War in Regional Politics. 8. Conclusions. References.

\section{INTRODUCCIÓN}

La Guerra del Golfo, en plena crisis soviética, fue el primer conflicto posterior a la caída del Muro de Berlín. La intervención de una coalición internacional liderada por Estados Unidos y la participación de España, cinco años después del referéndum sobre la permanencia en la OTAN, atrajeron la atención de millones de ciudadanos. El conflicto comenzó en 1990 con la invasión de Kuwait por las tropas iraquíes. España fue, tras Estados Unidos, el país con más enviados especiales y más equipos de televisión en la zona de conflicto (Pizarroso, 1991:39). El compromiso suscrito por el Gobierno español supuso un hito más en su historia contemporánea. La década de los ochenta contempló la incorporación definitiva del país al concierto internacional. Fruto del vínculo con Occidente, se autorizó el envío de dos fragatas y una corbeta como apoyo a la coalición.

Los medios de comunicación españoles recogieron con escepticismo la presencia de sus armas en el golfo Pérsico. La opinión pública refutaba mayoritariamente la guerra, aunque las protestas, más frecuentes según se intuía el desenlace, no fueron canalizadas por ninguna opción política mayoritaria. El antiamericanismo de la sociedad española (Sahagún, 1991:29; en Pizarroso, 1991), entendido como rechazo a la política exterior de Estados Unidos, su antimilitarismo y la apatía por los asuntos exteriores, favorecieron un sentimiento de rechazo y pronto restablecimiento de la paz.

La del Golfo se consideró la primera de las nuevas guerras (Pizarroso, 2005:31) y un conflicto eminentemente televisivo. La CNN se convirtió en la gran plataforma divulgadora de imágenes. Su penetración a través de los satélites, la fuerza del directo y la propia narrativa del conflicto alteraron la percepción sobre la guerra, convertida en espectáculo similar al cine o los videojuegos. También fue destacado el trabajo de centenares de cronistas de prensa. Sin embargo, la labor de los periodistas en la zona fue controlada por los mandos militares. La idea que trascendió apenas contenía sangre o muerte.

Los bombardeos de la coalición comenzaron el 17 de enero de 1991. Desde agosto del año anterior, Estados Unidos y sus aliados desplazaron tropas hasta Arabia Saudí. Los meses que separan la invasión de Kuwait por Irak y el inicio de la respuesta de la coalición sirvieron para organizar la ofensiva diplomática en Naciones Unidas e incluir a más de treinta países (varios de mayoría musulmana) en el seno del bloque aliado. También se orquestaron los preparativos militares y las campañas de propaganda para asegurar el beneplácito popular.

\section{METODOLOGÍA}

Se seleccionarán los medios de comunicación regionales cuya hemeroteca está disponible en la plataforma online del Centro de Estudios de Castilla-La Mancha (Biblioteca Virtual de Castilla-La Mancha) y que abordaron, entre sus informaciones, la Guerra del Golfo. Cuatro 
publicaciones que cumplen este requisito y se convierten en objeto de análisis: La Hoja Sindical, Lanza, Mirador de Almagro y Vecinos. El único con periodicidad diaria es Lanza y sobre dicha cabecera se establecerá el grueso de la investigación. Importantes medios impresos, como $A B C$ Toledo o las diferentes marcas de La Tribuna, no tienen sus archivos abiertos en internet.

Los medios escogidos permiten atender voces diferentes, poco frecuentes en los análisis hasta ahora realizados sobre esta guerra (centrados, grosso modo, en medios de mayor alcance y ámbito español). La prensa objeto de disección es minoritaria y de una región sin tradición de medios locales, pero tiene la capacidad de penetrar en el territorio e influir en amplios sectores sociales. La muestra posibilita abordar la proximidad entre medio y lector, una cercanía alejada del relato de los medios nacionales. Los cuatro periódicos elegidos favorecen la comprensión del sistema mediático castellano-manchego, estructura en la que conviven firmas nacionales con escasas referencias locales.

El período sobre el que se ejecuta el análisis corresponde a enero y febrero de 1991, siendo las fechas escogidas entre el 9 de enero y el 7 de febrero (30 días) de dicho año en el caso de la prensa diaria, y los números correspondientes a alguno de los dos meses en las otras publicaciones. El período de cobertura abarca tanto la crisis diplomática y las movilizaciones por la paz como el comienzo de los bombardeos y la actuación de la coalición. El seguimiento continuado de los hechos revelará la intensidad de la información, cómo fue mutando y su relación con otros temas nucleares para la sociedad castellanomanchega.

Respecto al corpus seleccionado, se analizarán aquellas informaciones propias aparecidas en las secciones relacionadas con la información local, provincial o regional. Dado el objeto de análisis, circunscrito a Castilla-La Mancha, serán descartadas aquellas piezas relativas al propio discurrir bélico, también los textos publicados en las secciones de nacional e internacional. Sólo se atenderá al enfoque castellano-manchego del conflicto (excepto en la portada, donde no importará el origen local o externo). El análisis cuantitativo recopilará el número de noticias que generó la guerra, señalando tanto su número como si aparecieron en la portada o fueron acompañadas de fotografía u otro recurso gráfico. El análisis cuantitativo, por su parte, atenderá la búsqueda del frame, entendido así al elemento propio del periodista que encuadra la realidad y desde el que expone su punto de vista (Sádaba, 2001:159), moldeador del mensaje y punto de contacto simbólico entre emisor y receptor capaz de alterar la percepción del último.

\section{LA NUEVA REGIÓN COMO RES POLÍTICA}

Castilla-La Mancha, territorio que coincide geográficamente con la meseta sur de la península ibérica, surge como comunidad autónoma tras la restauración democrática en España y el nuevo encaje territorial amparado por la Constitución de 1978. La región, surgida de la adición de cinco provincias, aprueba su Estatuto de Autonomía en 1982. Las primeras elecciones autonómicas se celebran en 1983. Gana el PSOE y José Bono es investido presidente. Entre los retos del primer líder, el del sentimiento colectivo por la nueva administración (Castellanos, 2007:86).

Los responsables políticos que diseñaron Castilla-La Mancha encontraron que nunca antes se había articulado en ese territorio, tampoco considerado en profundidad, un proyecto regional común. Una relevante peculiaridad en el desarrollo autonómico en Castilla-La Mancha fue el decisivo papel jugado en el mismo por los partidos políticos y sus élites 
dirigentes, un proceso de arriba abajo (Ortiz y otros, 2007:123).

En el invierno de 1991, José Bono se prepara para revalidar por tercera vez el cargo (elecciones en mayo). El desarrollo del regionalismo en Castilla-La Mancha, hasta entonces y con posterioridad, no sólo transcurrirá paralelo al éxito electoral del PSOE en las autonómicas o al aumento de la popularidad de su líder, sino que se encontrará directamente relacionado con ellos (Ortega y Luque, 2010:221). El discurso de Bono, referente ideológico de la región, también crea sentimiento de región (Mora, 1996:37).

La mimesis entre el PSOE y Castilla-La Mancha no traspasa la frontera regional. Entre la federación regional y la dirección federal existen diferencias; también entre los gobiernos autonómico y nacional, aunque compartan color. Así, Cabañeros, las Hoces del Cabriel o Anchuras se convierten en espacios emblemáticos del regionalismo castellano-manchego por constituir escenarios en los que la defensa de lo propio se impone a la supuesta voluntad insolidaria de intereses ajenos (Ortega y Luque, 2010:228). En Anchuras, un enclave natural en la provincia de Ciudad Real, el Ejecutivo regional se enfrentó al Ministerio de Defensa por su idea de militarizarlo y emplearlo como espacio para la práctica de tiro. El PSOE local se erigió, aprovechando su situación política, en portavoz y representante de los intereses de $s u$ ciudadanía.

\section{LA PRENSA DE CASTILLA-LA MANCHA EN LOS NOVENTA}

La prensa escrita, salvo escasas excepciones, no ayudó a la cohesión regional (Sánchez, 2001:207). Su índice de lectura en Castilla-La Mancha se ha mantenido muy por debajo de la media española (Fernández, 1998:3; Sánchez, 2001:206; Díaz, 2001:258). Tan pobre dato puede equipararse al de algunas naciones africanas (Armentia, 2005). También ha sido más baja la audiencia de radio y sólo el consumo de televisión ha resultado comparable, o incluso superior, al agregado estatal.

La prensa castellano-manchega, poco desarrollada en sus ediciones propias, dependía en buena medida de la madrileña: los periódicos más leídos se editaban allí y la prensa castellano-manchega local y provincial sobrevivía ligada a marcas nacionales, como el caso de $A B C$ Toledo, o en torno a grupos como La Tribuna, con ediciones distintas dentro del territorio regional. Aunque los noventa fueron propicios para la puesta en marcha de iniciativas periodísticas locales (Sánchez, 2001:207), la difusión de periódicos en las cinco provincias se mantuvo en cifras ínfimas, siendo Toledo la mejor de las castellano-manchegas (55 ejemplares por cada mil habitantes) y Cuenca la que peores cifras relativas mostró $(45,5)$. Según los datos del Instituto Nacional de Estadística de 1998 que desgrana Sánchez, sólo Jaén $(38,9)$ tenía un registro más bajo. La autora contrapone la divergencia entre las cabeceras habidas en Ciudad Real (más de veinte a finales de aquella década) y Guadalajara (sólo una). Para Díaz, la característica más destacada de la prensa de Castilla-La Mancha es su escasa penetración. La región ocupaba, según datos de 2001 recogidos por el autor, el último lugar entre todas las comunidades autónomas en consumo relativo de diarios $(19,4 \%$ frente al 35,9\% de media nacional).

Forman parte del corpus de esta investigación cuatro medios impresos. De ellos, tres no tienen periodicidad diaria y están vinculados a diferentes agentes sociales: La Hoja Sindical pertenecía al sindicato Comisiones Obreras (CC OO) en Toledo y se distribuyó entre sus afiliados; Mirador de Almagro fue un revista de actualidad del municipio ciudadrealeño homónimo publicada por su universidad popular; Vecinos era una iniciativa de la asociación vecinal El Tajo, del barrio del Polígono de Toledo. 
Por su parte, Lanza representa uno de los casos más curiosos del periodismo regional y español. Fundado en 1943, perteneció durante el franquismo a la denominada Prensa del Movimiento. Con la restauración democrática la cabecera quedó vinculada a la Diputación de Ciudad Real, constituyendo una excepción en el panorama mediático español, dada la ausencia de medios impresos de titularidad pública.

\section{ANÁLISIS INFORMATIVO DE LANZA}

Lanza es el único medio diario y el único verdaderamente periodístico de los cuatro seleccionados en esta investigación. La cobertura sobre la guerra fue habitual en la cabecera, destacando informaciones sobre las manifestaciones en favor de la paz, el temor por los efectos del conflicto y la situación de los soldados de remplazo y los insumisos. Informaciones de agencia, EFE y OTR (integrada después en Europa Press) principalmente, complementaron la información de proximidad y permitieron a los lectores de esta cabecera conocer el desarrollo del conflicto.

\subsection{Matriz cuantitativa}

Para facilitar el seguimiento de los datos y la comprensión del hecho informativo, los 30 ejemplares de Lanza analizados serán desagregados en seis bloques de cinco días cada uno.

Tabla 1: Contenidos sobre el conflicto en Lanza (I)

\begin{tabular}{|l|l|l|l|}
\hline & $\begin{array}{l}\text { ¿Aparece la guerra } \\
\text { en la portada? }\end{array}$ & $\begin{array}{l}\text { Número de textos } \\
\text { relacionados con la guerra }\end{array}$ & $\begin{array}{l}\text { ¿Presencia de fotografías } \\
\text { e imágenes? }\end{array}$ \\
\hline 9 de enero & Sí & 1 & Sí \\
\hline 10 de enero & Sí & 1 & No \\
\hline 11 de enero & Sí & 2 & Sí \\
\hline 12 de enero & Sí & 0 & No \\
\hline 13 de enero & Sí & 1 & No \\
\hline
\end{tabular}

Fuente: elaboración propia

Tabla 2: Contenidos sobre el conflicto en Lanza (II)

\begin{tabular}{|l|c|c|c|}
\hline & $\begin{array}{l}\text { ¿Aparece la guerra } \\
\text { en la portada? }\end{array}$ & $\begin{array}{l}\text { Número de textos } \\
\text { relacionados con la guerra }\end{array}$ & $\begin{array}{l}\text { ¿Presencia de fotografías } \\
\text { e imágenes? }\end{array}$ \\
\hline 14 de enero & Sí & 2 & Sí \\
\hline 15 de enero & Sí & 5 & Sí \\
\hline 16 de enero & Sí & 7 & Sí \\
\hline 17 de enero & Sí & 3 & Sí \\
\hline 18 de enero & Sí & 6 & Sí \\
\hline
\end{tabular}

Fuente: elaboración propia

Tabla 3: Contenidos sobre el conflicto en Lanza (III)

\begin{tabular}{|l|c|c|c|}
\hline & $\begin{array}{l}\text { ¿Aparece la guerra } \\
\text { en la portada? }\end{array}$ & $\begin{array}{l}\text { Número de textos } \\
\text { relacionados con la guerra }\end{array}$ & $\begin{array}{l}\text { ¿Presencia de fotografías } \\
\text { e imágenes? }\end{array}$ \\
\hline 19 de enero & Sí & 4 & Sí \\
\hline 20 de enero & Sí & 1 & Sí \\
\hline 21 de enero & Sí & 0 & No \\
\hline 23 de enero & Sí & 5 & Sí \\
\hline 2 denero & Sí & 1 & No \\
\hline
\end{tabular}

Fuente: elaboración propia 
Tabla 4: Contenidos sobre el conflicto en Lanza (IV)

\begin{tabular}{|l|c|c|c|}
\hline & $\begin{array}{l}\text { ¿Aparece la guerra } \\
\text { en la portada? }\end{array}$ & $\begin{array}{l}\text { Número de textos } \\
\text { relacionados con la guerra }\end{array}$ & $\begin{array}{l}\text { ¿Presencia de fotografías } \\
\text { e imágenes? }\end{array}$ \\
\hline 24 de enero & Sí & 3 & Sí \\
\hline 25 de enero & Sí & 2 & Sí \\
\hline 26 de enero & Sí & 0 & No \\
\hline 27 de enero & Sí & 1 & Sí \\
\hline 28 de enero & Sí & 1 & Sí \\
\hline
\end{tabular}

Fuente: elaboración propia

Tabla 5: Contenidos sobre el conflicto en Lanza (V)

\begin{tabular}{|l|c|c|c|}
\hline & $\begin{array}{l}\text { ¿Aparece la guerra } \\
\text { en la portada? }\end{array}$ & $\begin{array}{l}\text { Número de textos } \\
\text { relacionados con la guerra }\end{array}$ & $\begin{array}{l}\text { ¿Presencia de fotografías } \\
\text { e imágenes? }\end{array}$ \\
\hline 29 de enero & Sí & 2 & Sí \\
\hline 30 de enero & Sí & 1 & No \\
\hline 31 de enero & Sí & 1 & No \\
\hline 1 de febrero & Sí & 1 & Sí \\
\hline 2 de febrero & Sí & 0 & No \\
\hline
\end{tabular}

Fuente: elaboración propia

Tabla 6: Contenidos sobre el conflicto en Lanza (VI)

\begin{tabular}{|l|c|c|c|}
\hline & $\begin{array}{l}\text { ¿Aparece la guerra } \\
\text { en la portada? }\end{array}$ & $\begin{array}{l}\text { Número de textos } \\
\text { relacionados con la guerra }\end{array}$ & $\begin{array}{l}\text { ¿Presencia de fotografías } \\
\text { e imágenes? }\end{array}$ \\
\hline 3 de febrero & Sí & 1 & Sí \\
\hline 4 de febrero & Sí & 1 & No \\
\hline 5 de febrero & Sí & 4 & Sí \\
\hline 6 de febrero & Sí & 1 & Sí \\
\hline 7 de febrero & Sí & 1 & Sí \\
\hline
\end{tabular}

Fuente: elaboración propia

\subsection{Análisis cualitativo}

La cabecera diaria ciudadrealeña realizó una cobertura amplia del conflicto. Generó información propia en las secciones locales (Ciudad Real y otros municipios, Provincia y Región) y la complementó con textos de agencia que llenaron las áreas de Nacional e Internacional. Convirtió su suplemento de los domingos en una revista monográfica de la contienda y ofreció información sobre ella en páginas de cultura, economía y televisión. Asimismo, la guerra pasó a ser habitual en los espacios de opinión y humor gráfico.

Se informó desde la proximidad. Las movilizaciones contra la guerra, el rechazo al envío de soldados de remplazo al teatro de operaciones, el alza de los precios de ciertos productos por la subida del petróleo y el juicio contra los insumisos (rechazaban también la Prestación Social Sustitutoria) marcaron la agenda.

Uno de las primeras informaciones locales de alcance se fechó el lunes 14 de enero. Aquel día, posterior a una de las mayores manifestaciones de la crisis, la cobertura del periódico titulaba "La paz y la solidaridad, protagonistas de la concentración de ayer en El Pilar" y explicaba:

Con los gritos de fondo de "militares, parásitos sociales", "Bush, cuatrero”, "un bote, militar el que no bote" y "fuera, terroristas", algunos escolares leyeron comunicados escritos por alumnos de EGB de colegios de localidades como Alcázar de San Juan, Campo de Criptana, Alameda de Cervera y Herencia, que pertenecen al paquete de cartas remitidas a las embajadas de Irak y EEUU. Una de las misivas 
expuestas públicamente ayer estaba encabezada para "todos los gobiernos que intervienen en el conflicto del Golfo", enumerando las inevitables consecuencias de muertes inútiles y de pérdidas de miles y miles de niños.

Un día después, y ante la inminencia del comienzo de los ataques de la coalición, el medio centraba su atención en la base aérea de Albacete y llevaba la información a portada con el titular "Sin previsión especial en Los Llanos":

El coronel jefe de la Base Aérea de Los Llanos, José Antonio Cervera, reiteró ayer que no existe ninguna previsión especial e inminente para estas instalaciones militares en relación con el conflicto del Golfo Pérsico. El máximo responsable del Ala 14 declaró [...] que "el movimiento de aviones es el habitual" y que responde a los planes de entrenamiento diarios de los F-1 pero no "a ninguna preparación específica". Sobre el hipotético uso de las instalaciones albacetenses por las tropas de Estados Unidos en el caso de que estallase finalmente la guerra, el coronel Cervera afirmó, "a titulo estrictamente personal", que no creía que tal eventualidad se produzca ya que "por pura lógica operativa" los norteamericanos utilizarían en ese supuesto las bases a las que tienen acceso en virtud de los acuerdos firmados por ambos países.

Pasado el 15 de enero, fecha del ultimátum al régimen iraquí, creció el interés informativo ante la cercanía del desenlace. Aquel día, la noticia titulada "Acaparar alimentos", dentro de una pieza titulada "Toledo sigue en tensión el desarrollo del conflicto en el Golfo Pérsico", abordaba el alza de los precios de algunos productos básicos en la capital regional:

... se ha producido un incremento de las ventas de productos en general, que en algunos establecimientos ha sido del 15 por 100. Pero sobre todo, se están vendiendo productos como las legumbres, conservas, aceite y azúcar, todos aquellos productos que pueden ser almacenados. En lo que se refiere a estos alimentos, algunos supermercados [...] han experimentado un aumento en las ventas en torno al 50 por 100.

Ese día, la sección Ciudad Real publicaba una de las noticias más singulares de la investigación. Con el titular "Por la Guerra del Golfo, una pena doble" y el antetítulo "Dos hermanos de Ciudad Real en el conflicto", la pieza trataba la experiencia de Marta Martín Calero, de 14 años, cuyos hermanos cumplían el servicio militar enrolados en la Marina y tenían como destino los mares próximos a Irak. La joven entrevistada, cuya foto ilustraba el texto, contaba:

Por un hombre que sea un cabezota no tiene por qué haber guerra (sic) y no entiendo por qué se meten los países que no tienen culpa. Sobre todo que se lleven a mis hermanos como lo van a hacer.

El viernes 18 de enero, Lanza publicaba en portada y a cinco columnas una entrevista con el embajador iraquí en España. "No tenemos miedo a la guerra", decía el diplomático a Araceli Olmedo, colaboradora del periódico. La noticia, de indudable alcance, mejoró la cobertura que el medio impreso dio a sus lectores.

En la edición de aquel día, y en páginas de Región, se trataba la petición de un grupo de jóvenes al alcalde de Talavera de la Reina (Toledo). "Los estudiantes piden al alcalde que solicite el regreso de la Flota", rezaba un encabezado que iba precedido de un antetítulo tajante: "Estudian medidas de presión como cerrar comercios". En el texto, sin firma, se exponía: 
Algo más de mil estudiantes se manifestaron ayer. Por las calles de la Ciudad de la Cerámica con el fin de protestar por la recién desencadenada Guerra del Golfo. Con una pancarta en la que se podía leer 'Ni yankis ni moros, paz en el Golfo' el grueso de la manifestación recorrió las principales arterias de Talavera. La concentración se inició (...) enfrente de los edificios de los dos institutos de enseñanza media...

El 19 de enero, Lanza publicó la primera parte de un reportaje que se extendería al día siguiente y que exponía el pensamiento de los niños sobre el conflicto. Titulado "Los quintos del 2000 tienen miedo", la periodista Mercedes Pescador abría un debate con escolares ciudadrealeños de diez años (quienes habrían de hacer la mili en el año 2000) y sus impresiones sobre la guerra recién comenzada:

Un guirigay de voces confunde las opiniones y anima el debate en la escuela. A pesar de las palabras impacientes de los futuros quintos ciudadrealeños, algunas versiones cruzan el aire de la clase con nitidez: 'Antes de que mueran miles de soldados en la guerra que maten a Saddam', expresa un chaval. 'Pero dicen que es una guerra santa', indica otro... 'Hay un misil que puede alcanzar España. Los árabes tienen armas que pueden llegar hasta Andalucia', especifica. 'Sí porque ya estuvieron alli hace muchos años'...

La segunda parte del reportaje apareció al día siguiente. La información mantuvo el mismo titular. Los alumnos siguieron explicando sus argumentos respecto al conflicto.

'Los soldados se fueron al golfo con pocos días de mili hecha', advierte un alumno [...]: 'PPero si la mayoría no saben ni coger un fusil!', afirma Julián Suárez. Los chavales se preguntan lo que sentirán sus novias, sus padres... Sin embargo apoyan la guerra como la última solución al problema internacional y dicen que Saddam Hussein 'es el mayor culpable' del enfrentamiento armado en Oriente Medio. Es un avaricioso', expresa Alberto González. 'Por un sólo señor tenemos que pagar el mundo entero', se queja Jorge Jiménez. 'Si se unen todos los árabes se armará gorda ...', dice.

En el párrafo siguiente, podían leerse críticas de una alumna a los líderes políticos y de sus compañeros a la coalición. La charla con los escolares reproducía varios de los argumentos con que los medios explicaban qué pasaba.

... María Luisa Lorenzo opina que el presidente norteamericano George Bush y Saddam Hussein no dialogaron lo suficiente antes de usar la fuerza. Otros, como Pedro Martínez, consideran que la guerra no tiene por qué afectar a los europeos: "Que se peleen entre ellos dos y luego hablen", afirma. Todos confiesan tener miedo, porque dicen que "esta puede ser la tercera guerra mundial". Además los chavales han visto películas sobre el desastre de la guerra del Vietnam: "Alli cayeron los americanos porque desconocían el terreno. Lo mismo puede ocurrir ahora en el desierto", apunta.

El 22 de enero, Lanza narraba una manifestación frente al Tribunal Superior de Justicia de Castilla-La Mancha, cuya sede está en Albacete. La concentración era en favor de los seis insumisos que se negaban a realizar la Prestación Social Sustitutoria. "La calle era una fiesta", titulaba el periódico. En su primer párrafo, el periodista Justo L. Cirugeda contaba:

Las amas de casa se detenían atónitas, sin explicarse lo que estaba pasando en Albacete, y algunos niños escudriñaban como si se tratara de un número circense, 
mientras el exquisito público de las cafeterías del Paseo de la Libertad compartía su esparcimiento con desharrapados jóvenes procedentes de los movimientos alternativos de numerosas ciudades. La calle era ayer toda suya, y aunque el tiempo no acompañó, nada ni nadie hizo desistir a las huestes de la insumisión en su empeño por hacerse oír, $y$ de hecho en la planta tercera del Tribunal Superior de Justicia de Castilla-La Mancha, se escuchaban con más nitidez las consignas de protesta que las deliberaciones de la jueza, el fiscal, el abogado defensor o los testigos.

Pasaron los primeros días de guerra pero no bajó la intensidad del rechazo en la calle. El 28 de enero, el periódico llevaba en Local la crónica de otra acción de protesta. "Más manifestantes contra la guerra que en anteriores ocasiones", era el encabezado. En el cuerpo de la noticia se leía:

Santiago Martín, alcalde de Anchuras, señaló que la participación de los vecinos de la localidad en las movilizaciones por la paz va a continuar, apuntando que, "directa o indirectamente", la lucha contra el polígono de tiro forma parte de esa movilización; En lo que respecta a la ocupación de la finca de El Rosalejo, Martín expresó su satisfacción por cómo se desarrolló la iniciativa de ayer. El próximo paso a dar sería la ocupación total de la casa...

La manifestación contra la guerra permitía que asuntos de la agenda local, como Anchuras y El Rosalejo, sirvieran como marco de la protesta.

De los efectos económicos del conflicto se informó el 1 de febrero. Tras la publicación de textos sobre el alza en los comestibles, el petróleo y el ocio, llegó el turno de los sectores agrícola e industrial. "La crisis del Golfo daña la producción de hoces en La Solana", con el antetítulo de "Al igual que ocurre con el azafrán":

La preocupante crisis del Golfo Pérsico, convertida en guerra hace escasamente dos semanas, no sólo está haciendo doler la cabeza a los empresarios solaneros del azafrán, un producto que tiene gran capacidad de mercado en la zona del conflicto, sino que otro de los sectores importantes de la industria en La Solana, como son las hoces, también está viéndose seriamente afectado por el grave asunto. [...] la repercusión comenzó a notarse inmediatamente después del día 2 de agosto con la ocupación de Kuwait, "desde entonces hemos cancelado pedidos que alcanzan las 350.000 hoces, lo que supone una reducción de un 30 a 35 por ciento en la producción normal que veníamos haciendo".

La localidad ciudadrealeña de Tomelloso organizó, en torno al 30 de enero, la Semana de la Paz. Joaquín Ruiz-Giménez, entonces presidente del comité español de UNICEF (organismo de Naciones Unidas para la protección de la infancia), ofreció la conferencia de clausura. Lanza lo llevó en la edición del 3 de febrero:

Ruiz Giménez no se atrevió a pronosticar la duración del enfrentamiento bélico, pero apuntó su esperanza de que no sea demasiado largo porque "es insostenible que Irak se sobreponga a las fuerzas aliadas". [...] precisó que la guerra no será tan corta como en un principio todos imaginaban, y mostró su temor por el papel que interpreta Saddam Hussein al enarbolar la bandera de la guerra santa, [...] que "puede darle ánimos para prolongarla casi al suicidio”. En todo caso, si la guerra dura muchos meses supondrá "una catástrofe humana, económica y ecológica”,,...

Respecto a si el inicio del conflicto se pudo evitar, manifestó que la agresión de Irak "había que pararla pero a través de fórmulas distintas a la guerra". En este sentido, 
declaró que "es una trágica paradoja que esta guerra haya tenido que iniciarse en nombre de las Naciones Unidas".

El último de los textos extraídos para el análisis cualitativo trató la resolución del juicio de los insumisos, proceso seguido con regularidad e interés por esta cabecera. "Los seis insumisos, condenados a dos años, cuatro meses y un día de cárcel", fue el titular de Lanza:

... el abogado defensor, señaló que sus representados no recurrirán la sentencia porque [...] se trata [...] de hacer valer el derecho de toda la gente a seguir viviendo en paz, en un mundo no marcado por la violencia y las armas. El letrado, al igual que los insumisos manifestaron (sic) que en ningún momento han negado los cargos que se les imputaban [...]. Por el contrario, los reconocieron y proclamaron a cuatro vientos, pues son "actos no ya positivos para la sociedad en que se vive, sino incluso, dignos de imitación, y con una base muy profunda en los propios valores y principios que basan nuestro ordenamiento. Actos, por tanto, que deben tener el amparo de la ley y no el repudio".

\section{ANÁLISIS INFORMATIVO DE LOS OTROS MEDIOS}

Las otras tres publicaciones que forman la investigación sólo aportan un ejemplar cada una. Se trata de medios de escasa importancia y difusión, sin peso informativo y volcados en los géneros periodísticos de opinión, pero que complementan la mirada de Lanza y permiten atender el enfoque del conflicto que tuvieron diferentes instituciones.

\subsection{Análisis de La Hoja Sindical}

\subsubsection{Matriz cuantitativa}

Tabla 7: Contenidos sobre el conflicto en La Hoja Sindical

\begin{tabular}{|l|l|c|c|}
\hline & $\begin{array}{l}\text { ¿Aparece la guerra } \\
\text { en la portada? }\end{array}$ & $\begin{array}{l}\text { Número de textos } \\
\text { relacionados con la guerra }\end{array}$ & $\begin{array}{l}\text { ¿Presencia de fotografías } \\
\text { e imágenes? }\end{array}$ \\
\hline $\begin{array}{l}\text { La Hoja } \\
\text { Sindical }\end{array}$ & $\begin{array}{l}\text { Sí. "Por la Paz, No } \\
\text { a la Guerra". }\end{array}$ & 2 & No \\
\hline
\end{tabular}

Fuente: elaboración propia

\subsubsection{Análisis cualitativo}

El número de La Hoja Sindical analizado, del 15 de enero de 1991, aborda la Guerra del Golfo como la noticia más destacada de su portada. El titular de este periódico mensual expone con nitidez la postura del sindicato $\mathrm{CC}$ OO, vinculado a Izquierda Unida, respecto a una ofensiva que habría de empezar dos días después pero que se creía inevitable. "Por la $P a z$, No a la Guerra”, rezaba el encabezado. A continuación se reproducía el manifiesto leído en las marchas contra la guerra que habían tenido lugar el domingo 13 de enero en diferentes ciudades, también Toledo. No se mostraba información gráfica. El ejemplar sólo tenía dos páginas y en ambas había referencias al conflicto.

En páginas interiores y en una tribuna de opinión firmada con seudónimo, se insistía en la idea de paz. "Por la Paz" se titulaba el texto, cuyo último párrafo expresaba: "Un día, un pueblo culto, mandará a la mierda a sus dirigentes militaristas, a sus sacerdotes y a sus dioses y se dedicará simplemente a vivir en paz".

\subsection{Análisis de Mirador de Almagro}




\subsubsection{Matriz cuantitativa}

Tabla 8: Contenidos sobre el conflicto en Mirador de Almagro

\begin{tabular}{|l|c|l|c|}
\hline & $\begin{array}{l}\text { ¿Aparece la guerra } \\
\text { en la portada? }\end{array}$ & $\begin{array}{l}\text { Número de textos } \\
\text { relacionados con la guerra }\end{array}$ & $\begin{array}{l}\text { ¿Presencia de fotografías } \\
\text { e imágenes? }\end{array}$ \\
\hline $\begin{array}{l}\text { Mirador de } \\
\text { Almagro }\end{array}$ & No & 2 & No \\
\hline
\end{tabular}

Fuente: elaboración propia

\subsubsection{Análisis cualitativo}

El número de Mirador de Almagro seleccionado corresponde al 1 de febrero de 1991. En esta revista mensual de información local no hay referencias a la Guerra del Golfo en la portada, ocupada íntegramente por la próxima celebración del carnaval. El ejemplar analizado tenía 36 páginas. El editorial, sin título y que firma F.R., comienza su relato en la noche del 16 de enero:

... mientras los habitantes de Almagro nos reuníamos en torno a la hoguera [probable referencia a la víspera de la festividad de san Antón], otra hoguera mucho más cruel, mucho más inhumana, se encendía. Era la hoguera de la guerra.

La idea del editorialista consiste en acercar el conflicto al lector, hacerlo cercano y adaptarlo a la realidad diaria de sus lectores. Significativo es el siguiente párrafo:

Los medios de comunicación se movilizaron para dar noticias de la guerra quitándonos, una vez más, algunas horas de sueño a muchos españoles que permanecimos atentos al televisor o a la radio para conocer el desarrollo de los acontecimientos, y el alma se nos encogió ante el sonido de los proyectiles y la narración de los periodistas. En los días sucesivos estuvimos atentos al desarrollo de los acontecimientos hasta que, cuando ha pasado una semana, la guerra se nos ha hecho algo cotidiano [...] incluso los informativos de la radio y la televisión se han reducido a los normales, los programas especiales sobre el desarrollo de la guerra se han reducido ostensiblemente. En la calle se habla de la guerra, sí, pero se habla mucho más de aquello que nos sucede en nuestro entorno...

Además del editorial, este ejemplar publicó dos textos más sobre la guerra. Una pieza de opinión titulada "El presidente de los EE UU no ve "Cristal"” comparaba el conflicto como la popular telenovela, en tanto ambos parecían "culebrones" de difícil resolución. El texto, firmado por Montse Rayo, consideraba la guerra como un "drama al que se ha empeñado este señor [George Bush], para hacernos representar a los demás un papel que no nos gusta". No hay referencia alguna a Saddam Hussein y sí varias menciones al presidente estadounidense, tanto con su nombre como por su cargo. Sobre la participación española, la columnista opina:

Y menos mal, que nuestros "managers" (sic), han conseguido (a pesar de las presiones de los grandes), que ante la guerra de los "golfos" (que son varios y no geográficos precisamente), sólo desempeñemos el papel de "apuntadores", detrás de los "decorados", aunque por el momento parece que en esta película no va a morir el apuntador.

Una pieza más apareció en este número. Sin embargo lo hizo bajo el cintillo de Internacional, circunstancia que lo deja fuera de la investigación. El artículo se titulaba 
"Nuevo Orden Mundial" y lo firmaba Ana Parra Ramírez. Esta pieza es la única de las tres que iba ilustrada con una fotografía.

\subsection{Análisis de Vecinos}

\subsubsection{Matriz cuantitativa}

Tabla 9: Contenidos sobre el conflicto en Vecinos

\begin{tabular}{|c|l|c|c|}
\hline & $\begin{array}{l}\text { ¿Aparece la guerra en } \\
\text { la portada? }\end{array}$ & $\begin{array}{l}\text { Número de textos } \\
\text { relacionados con la guerra }\end{array}$ & $\begin{array}{l}\text { ¿Presencia de } \\
\text { fotografias e imágenes? }\end{array}$ \\
\hline Vecinos & $\begin{array}{l}\text { Sí. "El terror, la } \\
\text { sangre y la barbarie". }\end{array}$ & 4 & Sí \\
\hline
\end{tabular}

Fuente: elaboración propia

\subsubsection{Análisis cualitativo}

El ejemplar de Vecinos analizado corresponde a los meses de enero y febrero. Se trata de una publicación amateur que informa de la actividad en el barrio de Santa María de Benquerencia - conocido como El Polígono- de Toledo. Este periódico gratuito tenía una difusión de 4.000 ejemplares. La guerra también apareció en el primer número de 1991, de 16 páginas de extensión.

En la columna de la portada, en el lado derecho de la misma, se llama a ambos líderes, iraquí y estadounidense "monstruos", diciendo "qué horror y asco dan los dos". Uno de los párrafos de la columna añade sobre los presidentes:

Dos locos de poder y sangre, si el uno se lanza a una invasión frenética, el otro niega la posibilidad de parar la guerra en su momento más álgido, él y sólo él nos impide esta posibilidad. Los lacayos, serviles, callan, y humillados asienten la voz de su amo, por si les castiga con represalias. El amo quiere un escarmiento sangriento y ejemplar, una lección moral, nada de Paz. Nos la da el mayor invasor, el primero que usó las armas nucleares horrorizando al mundo, el primero en utilizar armas químicas, el mayor explotador de los pueblos...

La información aparece en la portada, aunque no es la noticia más destacada. "El terror, la sangre y la barbarie", es el encabezado de la misma, prologado con el antetítulo de "Dos caras de la misma moneda". Sendas fotografías de Saddam Hussein y George Bush acompañan al texto.

En las páginas interiores hay más información referida a la Guerra del Golfo. En la página ocho se puede leer un texto titulado “¿Insumisión; por qué no?”, escrito por Ángel Dorado y al que acompañaba una viñeta de El Roto, célebre dibujante de la prensa española. En la misma página se reproducía el comunicado de la Confederación de Asociaciones de Vecinos.

Estamos muy lejos todavía de que en España nadie sea forzado a ir al servicio militar y por algo que pensado desde la conciencia individual, no hace daño a nadie, por el respeto más profundo hacia aquellos que bajo ningún concepto desean ir obligados al ejército, y menos a una zona en conflicto bélico, es tremendamente doloroso e injusto, (la Ley porque sea Ley no quiere decir que sea justa) que se juzgue y condene a jóvenes insumisos o que otros se conviertan en desertores por una Ley caduca y obsoleta que cambiará irremisiblemente, esperemos que pronto, y en tanto en cuanto desaparece el ejército hay que ir a un ejército profesional y democrático, eliminando el servicio militar obligatorio, ¿utopía? ¡Pues viva la utopía!

Más adelante, y sobre una extensión de tres páginas, podía leerse un largo texto llamado 
"Los barrios por la Paz. El desarrollo de la conciencia pacifista en los barrios". Otras tres viñetas, una por página incluyendo una paloma, complementaban la letra. A través de tres puntos, (Origen y consecuencias de la actual carrera de armamentos / La situación en el Estado español / Los gastos militares), se desarrollaba argumentalmente el rechazo a la guerra, poniendo el foco en el pacifismo, el no a la OTAN y el dinero gastado, tanto en España como en el resto del mundo, en políticas y herramientas de defensa. Del presupuesto gastado, la tribuna explicaba:

a) España fue el país que más armas compró en 1984. b) Las inversiones militares han supuesto durante el pasado año, más de 30 veces los presupuestos del Ministerio de Cultura o de Sanidad. c) La previsión de gasto en armamento hasta 1.990 es de 2 billones y medio, aproximadamente unos 2.000 millones de pesetas diarias. d) Las inversiones en gastos militares han superado el $3 \%$ recomendado por la OTAN, situándose en España en el 3,4\% del Producto Interior Bruto.

Por último, en la página trece de Vecinos figuraba un texto, junto a una ilustración de un arma rodeado de ramas de olivo, titulado "Brindis para después de una guerra", de Jesús Mateo Hernández. El texto, con marcada vocación lírica, terminaba: ' $Y$ el mundo / quede en paz, / tranquilamente exangüe, / primorosamente deshabitado'.

\section{LA GUERRA EN LA POLÍTICA REGIONAL}

El Gobierno de Castilla-La Mancha fue un actor sin relevancia en la crisis del Golfo. El escaso interés que las cuestiones exteriores suscitaban en la población española, además de la percepción de que el rumbo internacional tomado en aquellos años era el correcto (SánchezCuenca y Barreiro, 2000:29) pudo verse agravado en Castilla-La Mancha, región de interior, sin fronteras ni salida al mar. El grueso de las explicaciones en materia de seguridad vino desde la Delegación del Gobierno en la región y de las extintas Gobernaciones Civiles. Formaciones como Izquierda Unida (IU) o el Centro Democrático Social (CDS), que se opusieron a la guerra, son citados con más frecuencia que el PSOE, que sostenía al Ejecutivo regional. Tampoco destacan las menciones a la principal fuerza de oposición, el Partido Popular (PP).

No parecía existir en la ciudadanía castellano-manchega un sentimiento de rechazo por lo militar. En el referéndum sobre la permanencia en la OTAN de marzo de 1986, Castilla-La Mancha fue una de las dos regiones (la otra, Andalucía) en la que los votos afirmativos superaron el umbral del $60 \%$. El deseo de paz, mayoritario en la sociedad española según las encuestas publicadas y a tenor de las movilizaciones populares, puede explicarse a través de distintas causas o de la concatenación de las mismas: temor ante lo desconocido, recuerdo de la guerra civil, fortaleza de la idea de paz (la iglesia católica condenó la guerra), tropas desplazadas y posibles represalias.

El discurso de la administración de Castilla-La Mancha consistió en explicar la guerra desde el compromiso de España con la comunidad internacional, el deseo de paz y pronta resolución y el carácter humanitario de la misión española. El 15 de enero, Lanza reunía unas declaraciones del presidente de la región, José Bono, sobre la base aérea de Los Llanos, en Albacete:

Por otra parte, el presidente (...) José Bono negó ayer en Albacete tener conocimiento de que la Base de los Llanos esté llamada a desempeñar un papel "especial" en caso de guerra. "Si tuviese que ser asi", declaró a LANZA José Bono, 
"en algún momento tendría esa información, pero no la tengo, lo cual me hace sentir esperanza de que no se produzca la eventualidad trágica de la guerra”.

Aquel día, un diputado regional del CDS pidió a las Cortes de Castilla-La Mancha una reunión de la diputación permanente ante la escalada de tensión en el golfo Pérsico y el sospechado desenlace. El presidente del Parlamento autonómico, del PSOE, negó la demanda:

Según informaron fuentes de las Cortes Regionales de Castilla-La Mancha, el presidente (...) José Manuel Martínez Cenzano, no tiene intención de reunir a la diputación permanente de las Cortes para cursar la petición formulada por el diputado del CDS, José Deogracias Carrión. Este diputado solicitaba al presidente que convocará a. la diputación permanente para formular una declaración institucional en la que se hiciese constar y en la que se instara al Parlamento y al Gobierno central a que apoyaran de forma plena las resoluciones de las Naciones Unidas en el conflicto del Golfo Pérsico.

El 24 de enero, el diputado socialista por Ciudad Real Miguel Ángel Martínez aseguró, y así tituló Lanza, que "La invasión de Kuwait ataca al nuevo orden mundial". El político defendió la actuación de la coalición internacional y el posicionamiento de su partido:

El diputado socialista indicó que la invasión de Kuwait y los hechos posteriores ocurridos en este país son una flagrante violación de los derechos humanos, con la cual Irak se pone al margen de las naciones civilizadas. Finalmente, según dijo Martínez, la invasión de Kuwait es un ataque frontal al nuevo orden mundial de paz y de superación de la "guerra fría". Para Martínez, la comunidad internacional reaccionó como era debido y como estaba previsto en las resoluciones de la ONU. Una reacción que con una unanimidad y firmeza que tiene escasísimos precedentes y que está en sintonía con el orden mundial...

... afirmó que el papel de España en el conflicto era "absolutamente digno". Rechazó las críticas de los que creían que España debería de retirar sus barcos del Golfo Pérsico y señaló que nuestro país está jugando está en consonancia de lo acordado en la ONU, y que no estar implicado en este conflicto hubiera sido una vuelta a los tiempos del aislacionismo. Añadió que se está actuando en el camino de conseguir un mundo mejor (...). Por último, Martínez crítico en tono duro la actitud de la Conferencia Episcopal...

\section{CONCLUSIONES}

La prensa escrita de la región apostó por una cobertura de cercanía que abordó los intereses más inmediatos. Las movilizaciones en favor de la paz y contra la solución bélica, el papel de los soldados desplazados, la preocupación de sus familiares, los objetores de conciencia - con los seis insumisos de Albacete de fondo-y el alza en los precios de algunos productos marcaron el grueso de las informaciones. Sobre la guerra se generó un discurso estereotipado pero cercano: se publicaron piezas de elaboración propia que atendieron las consecuencias cotidianas entre la ciudadanía de la región. Se atendió el miedo por la economía, se cubrieron manifestaciones en pueblos y ciudades y se trató la inquietud de los jóvenes por el servicio militar obligatorio.

En la prensa española la cobertura de la guerra se caracterizó por la simbiosis entre el 
discurso político y el mediático. Desde el Gobierno se generó un relato que asumieron los medios de comunicación. En la preparación de la narrativa prebélica no faltaron mentiras y medias verdades sobre el régimen iraquí y la ocupación de Kuwait (Pizarroso, 2008:8). El acierto del Ejecutivo liderado por Felipe González permitió decantar progresivamente a la opinión pública española en favor de la intervención armada: de un amplio rechazo se pasó a la aceptación resignada. En Castilla-La Mancha Lanza asumió ese marco, aunque los medios locales y ligados a instituciones diversas se mostraron contestatarios. La intervención española se vendió como inevitable y necesaria, aunque no faltaron críticas por la falta de transparencia del Ejecutivo socialista y la actitud bélica de los aliados (Estados Unidos especialmente).

La información de servicio público (precios, productos, manifestaciones) fue habitual durante los primeros días de bombardeos. Otro argumento en la prensa castellano-manchega fue la situación de los soldados de la región destacados en la zona de operaciones, prestando, asimismo, espacio a los familiares que esperaban su regreso. También se indagó cómo los niños veían el conflicto. Los escolares reprodujeron en sus declaraciones los argumentos con que los medios de comunicación y la clase política lo explicaban. Las asociaciones de vecinos, muy activas durante la Transición, y los sindicatos, sí manifestaron abiertamente su rechazo y cargaron contra Estados Unidos, lo militar y el Gobierno socialista por haber llevado a España a la guerra traicionando sus promesas respecto a la OTAN primero y la relación con Estados Unidos después.

Entre los medios seleccionados, sólo Lanza mantuvo el enfoque informativo (apenas valorativo), brindando un tratamiento serio, regular y extendido en el tiempo. Alrededor del 17 de enero, fecha del inicio de los bombardeos sobre Irak, el número de textos relacionados aumentó. Las otras publicaciones impresas atendieron la guerra desde la lógica superficialidad (escasez de medios y periodicidad no diaria) y a través de la óptica particular de los intereses de cada cual; como ejemplos, la publicación que edita un sindicato pidió la paz y llamó a los trabajadores a detener un conflicto tildado de imperialista; una revista local estableció paralelismos entre las hogueras tradicionales de su fiesta y el fuego de la guerra. Las publicaciones minoritarias se convirtieron en contenedores de textos de opinión. Frente al equilibrio de Lanza, poco dado a la interpretación en sus informaciones, los medios no profesionales cargaron más culpas sobre Estados Unidos y criticaron con mayor dureza la decisión del Gobierno español.

En los cuatro medios analizados fue notable el peso de la imagen. Abundaron las fotografías, las ilustraciones y cualquier icono que tuviera una importante carga simbólica. En el caso de Lanza, hubo apoyo gráfico en la portada 20 de los 30 días del corpus seleccionado; además, buena parte de sus crónicas y reportajes llevaron fotografias propias.

Entre los frames utilizados destacan las ideas de miedo, paz, petróleo, sangre, gasto militar, imperialismo, derecho internacional y nuevo orden mundial. Estos conceptos, simples y que sirven de marco para la información, facilitaron la explicación al lector de una crisis compleja como fue la Guerra del Golfo.

La narrativa mediática regional se inspiró en la nacional: ambos grupos apostaron por las fotografías, por la inclusión de datos y estadísticas que aportaran apariencia de veracidad, y por un enfoque militarizado y muy tecnológico. En el ámbito castellano-manchego, Lanza imitó el discurso recurrente en la prensa nacional, aportando una mirada sosegada en sus informaciones y recogiendo la explicación ofrecida por la clase política. Los frames empleados coincidieron con los que utilizaron las principales cabeceras españolas, especialmente La Vanguardia y El País -en menor medida con ABC-(Morera, 2017:30-31): entre lo inevitable de la guerra y la equidistancia entre bandos. Sin embargo, los medios 
regionales no ligados a empresas periodísticas tomaron partido por la contestación y apostaron por dar voz a los sectores más críticos y que protagonizaron el grueso de las movilizaciones, como los jóvenes (Pérez y Bretones, n.d.:73).

El Gobierno regional, liderado por el PSOE, sostuvo una postura similar a la del nacional aunque introdujo algún matiz en su narrativa, adoptando una diferenciación que encajara en la visión autorreferencial de la región y favoreciendo una narrativa propagandística en defensa de lo más próximo. Se ligó el conflicto bélico con el problema de Anchuras; se adoptó un perfil bajo sobre una crisis que trascendía las competencias y el ámbito regional.

La lucha de los insumisos contra la objeción de conciencia fue otro de los grandes temas de la agenda mediática. Parte del contingente español en Oriente Próximo lo formaban chicos que hacían el servicio militar obligatorio. Destacado fue el caso de los seis insumisos de Albacete, cuyo juicio se celebró coincidiendo con las primeras semanas de intervención militar en Kuwait e Irak. Dada la cobertura que le brindaron los medios locales fue este asunto uno de los más relevantes en Castilla-La Mancha, importante también para la prensa nacional (Oliver, n. d.:119-120), y factor diferencial del clima sobre la guerra en esta región respecto al resto de España.

\section{BIBLIOGRAFÍA}

Armentia Vizuete, J. I. (2005) El diario de servicios: la consolidación de un nuevo modelo informativo. Características generales de la prensa en España (curso de doctorado). Euskal Herriko Unibertsitatea, http://www.ehu.eus/jiarmentia/doctorado/doctorado2005 /tema7.html [consulta 8/9/2017].

Castellanos López, J. (2005) La transición democrática en Castilla-La Mancha 1976-1983. Proceso autonómico y construcción regional (tesis doctoral). Albacete: Universidad de Castilla-La Mancha, accesible en: https://goo.gl/6bVwBr [consulta 17/5/2018].

Díaz Revorio, F. J. (2002) La situación de los medios de comunicación social en Castilla-La Mancha. Parlamento y Constitución, 6: 255-272, https:/goo.gl/szQJsZ [consulta 12/1/ 2018].

Fernández Obregón, F. J. (1998) "La prensa periférica española". Revista Latina de Comunicación Social, 2 https://goo.gl/pGNbQV [consulta 10/8/2017].

La Hoja Sindical. Ceclmdigital2.uclm.es. (2017) Biblioteca Virtual de Castilla-La Mancha - Prensa, https://goo.gl/H8m5uA [consulta 8/9/2018].

Lanza. Ceclmdigital2.uclm.es. (2017) Biblioteca Virtual de Castilla-La Mancha - Prensa, https://goo.gl/cyc7dr [consulta 8/10/2017].

Morera Hernández, C (2012) “Operación 'Tormenta del Desierto': guerra y encuadres noticiosos en la prensa española (1991)”. Razón y Palabra, 79: 1-34, https://goo.gl/xobPhA [consulta 14/11/2017].

Mirador de Almagro. Ceclmdigital2.uclm.es. (2017) Biblioteca Virtual de Castilla-La Mancha Prensa, https://goo.gl/LcVswm [consulta 8/11/2017].

Mora Rodríguez, F. (1996) "Aproximación al discurso político en Castilla-La Mancha". Añil: Cuadernos de Castilla - La Mancha, 10: 37-39, https://goo.gl/HqiB4c [consulta 25/5/2018].

Oliver Olmo, P. (n.d.). "IV. La dinámica interna y el protagonismo social de los grupos de objeción, insumisión y deserción". En: El movimiento de insumisión durante el conflicto del Golfo Pérsico. [Online] Albacete: Universidad de Castilla-La Mancha https://goo.gl/DKxbp7 [consulta 08/09/2018].

Ortega Ruiz, M. y Luque Castillo, F. (2010) "Los presidentes autonómicos como regional-makers. El caso de José Bono en Castilla-La Mancha". Barataria. Revista Castellano-Manchega de Ciencias Sociales, 11: 219-230, DOI: http://dx.doi.org/10.20932/barataria.v0i11.161

Ortiz Heras, M., Castellanos López, J. y Martín García, Ó. (2007) "Historia social y política para una transición. El cambio desde abajo y la construcción de una nueva autonomía: Castilla-La Mancha". HOAL, 14: 115-126. 
Pérez, M. y Bretones, M. (n.d.) “1991: Las movilizaciones contra la Guerra del Golfo y la crisis de opinión", pp.1-125, https://goo.gl/Qc9SeV [consulta 6/2/2018].

Pizarroso, A. (2009) “Aspectos de propaganda en los conflictos armados”. Redes Com, 5: 49-65.

Pizarroso, A. (2008) "Justificando la guerra. Manipulación de la opinión pública en los conflictos más recientes". Comunicación: Revista Internacional de Comunicación Audiovisual, Publicidad y Estudios Culturales, 6: 3-19.

Pizarroso, A. (1991) La guerra de las mentiras. Madrid: Eudema.

Pizarroso, A. (2005) Nuevas guerras, vieja propaganda (de Vietnam a Irak). Valencia: Universitat de València.

Sádaba, T. (2001) "Origen, aplicación y límites de la 'teoría del encuadre' (framing) en comunicación”. Communication \& Society, 14(2): 143-175.

Sánchez-Cuenca, I., Barreiro, B. (2000) Los efectos de la acción de gobierno en el voto durante la etapa socialista (1982-1996). Madrid: Centro de Investigaciones Sociológicas, Opiniones y actitudes, $\mathrm{n}^{\circ} 29$.

Sánchez Jara, C. (2001) "La realidad informativa próxima”. En: T. Fernández García y A. García Rico, (Eds.) Medios de comunicación, sociedad y educación. Cuenca: Ediciones de la Universidad de Castilla-La Mancha, pp. 203-210.

Sánchez Sánchez, I. (1998) "Castilla-La Mancha contemporánea”. Añil: Cuadernos de Castilla - La Mancha, 15: 69-71 https://goo.gl/WDLXtT [consulta: 3/3/2018].

Vecinos. Ceclmdigital2.uclm.es. (2017) Biblioteca Virtual de Castilla-La Mancha - Prensa. https://goo.gl/mFTPEq [consulta 8/9/2018].

\section{Breve currículo:}

\section{Álvaro de la Paz González}

Licenciado en Periodismo por la UCM, máster en Formación del Profesorado en las especialidades de Geografía, Historia e Historia del Arte por la UCLM, y doctorando en Periodismo por la UCM. Ha publicado artículos periodísticos en la edición online de El País, en Politikon y en La Tribuna de Toledo. Investiga, desde octubre de 2015, en los campos de la propaganda y la opinión pública y en la influencia que sobre los mismos ejercen los medios de comunicación. Su proyecto de tesis se titula Análisis comparativo de la propaganda en España durante las guerras del Golfo (1991) e Irak (2003): la efectividad de los discursos político y mediático en la opinión pública. 